Article

\title{
Simultaneous Detection of Ammonium and Nitrate in Environmental Samples Using on Ion-Selective Electrode and Comparison with Portable Colorimetric Assays
}

\author{
Jittima Choosang 1,2,3, Apon Numnuam 2,3, Panote Thavarungkul 2,4, \\ Proespichaya Kanatharana ${ }^{2,3}$, Tanja Radu ${ }^{5}$, Sami Ullah ${ }^{6}$ and Aleksandar Radu ${ }^{1, *(D)}$ \\ 1 The Birchall Centre, Lennard-Jones Laboratories, Keele University, Keele ST5 5BG, UK; \\ Jittima_ch@hotmail.com \\ 2 Trace Analysis and Biosensor Research Center, Prince of Songkla University, Hat Yai 90112, Thailand; \\ anumnuam@gmail.com (A.N.); panote.t@psu.ac.th (P.T.); proespichk@gmail.com (P.K.) \\ 3 Department of Chemistry, Faculty of Science, Prince of Songkla University, Hat Yai 90112, Thailand \\ 4 Department of Physics, Faculty of Science, Prince of Songkla University, Hat Yai 90112, Thailand \\ 5 School of Architecture, Building and Civil Engineering, Loughborough University, Ashby Road, \\ LE113TU Loughborough, Leicestershire, UK; t.radu@lboro.ac.uk \\ 6 School of Geography, Earth and Environmental Sciences and Birmingham Institute of Forest Research, \\ University of Birmingham, B15 2TT Birmingham, Edgbaston, UK; S.Ullah@bham.ac.uk \\ * Correspondence: a.radu@keele.ac.uk
}

Received: 4 September 2018; Accepted: 4 October 2018; Published: 19 October 2018

Abstract: Simple, robust, and low-cost nitrate- and ammonium-selective electrodes were made using substrate prepared from household materials. We explored phosphonium-based ILs and poly (methyl methacrylate)/poly(decyl methacrylate)(MMA-DMA) copolymer as matrix materials alternative to classical PVC-based membranes. IL-based membranes showed suitability only for nitrate-selective electrode exhibiting linear concentration range between $5.0 \times 10^{-6}$ and $2.5 \times 10^{-3} \mathrm{M}$ with a detection limit of $5.5 \times 10^{-7} \mathrm{M}$. On the other hand, MMA-DMA-based membranes showed suitability for both ammonium- and nitrate-selective electrodes, and were successfully applied to detect $\mathrm{NO}_{3}{ }^{-}$and $\mathrm{NH}_{4}{ }^{+}$in water and soil samples. The proposed ISEs exhibited near-Nernstian potentiometric responses to $\mathrm{NO}_{3}{ }^{-}$and $\mathrm{NH}_{4}{ }^{+}$with the linear range concentration between $5.0 \times 10^{-5}$ and $5.0 \times 10^{-2} \mathrm{M}(\mathrm{LOD}=11.3 \mu \mathrm{M})$ and $5.0 \times 10^{-6}$ and $1.0 \times 10^{-3} \mathrm{M}(\mathrm{LOD}=1.2 \mu \mathrm{M})$, respectively. The power of ISEs to detect $\mathrm{NO}_{3}{ }^{-}$and $\mathrm{NH}_{4}{ }^{+}$in water and soils was tested by comparison with traditional, portable colorimetric techniques. Procedures required for analysis by each technique from the perspective of a non-trained person (e.g., farmer) and the convenience of the use on the field are compared and contrasted.

Keywords: ion-selective electrodes; environmental analysis; soil analysis; electrodes versus colorimetric assay

\section{Introduction}

Fertilizer use has been essential to feed half of the world's population over the 20th century and will be fundamental to ensure global food security over the 21st century. Interestingly, approximately $2 \%$ of world energy use is dedicated to the industrial manufacture of reactive nitrogen $\left(\mathrm{N}_{\mathrm{r}}\right)$ mainly through the Haber-Bosch process to produce ammonia. Worryingly, the efficiency of nutrient use is very low: on average over $75 \%$ of added nutrients end up lost to the environment, thus causing pollution either of water systems or through emissions of highly potent greenhouse gases $\mathrm{N}_{2} \mathrm{O}$ and 
$\mathrm{NH}_{3}$, and carcinogens such as $\mathrm{NO}_{2}$. One report suggests that a $20 \%$ improvement in nutrient use efficiency would reduce use of nitrogen fertilizer by 20 million tonnes annually. This in turn could produce a net saving worth around $£ 110$ billion per annum [1].

Nitrogen is used by plants in the forms of nitrate $\left(\mathrm{NO}_{3}{ }^{-}\right)$and ammonium $\left(\mathrm{NH}_{4}{ }^{+}\right)$[2]. These ions are produced by nitrification process; $\mathrm{NO}_{3}{ }^{-}$production includes ammonium $\left(\mathrm{NH}_{3}\right)$ oxidation to nitrite $\left(\mathrm{NO}_{2}{ }^{-}\right)$followed by $\mathrm{NO}_{2}{ }^{-}$oxidation to $\mathrm{NO}_{3}{ }^{-}$. On the other hand, $\mathrm{NH}_{4}{ }^{+}$in soil is produced by the reduction of $\mathrm{NO}_{3}{ }^{-}$[3]. So, these ions can exist together in soil due to the use of fertilizers in soil, agricultural cultivation, nitrogen fixation, and animal waste [4]. While being extremely useful in agriculture due to their leaching, $\mathrm{NO}_{3}{ }^{-}$and $\mathrm{NH}_{4}{ }^{+}$ions in soil may cause pollution and become a major ecological problem in agricultural areas. For example, concentrations of $\mathrm{NO}_{3}{ }^{-}$in water are taken as indicators of water quality. The Ministry of Health with the European Council sets the highest limiting value of nitrate $50 \mathrm{mg} \cdot \mathrm{L}^{-1}$ and $15 \mathrm{mg} \cdot \mathrm{L}^{-1}$ in drinking water and water for infants, respectively [5]. Therefore, simultaneous determination of $\mathrm{NO}_{3}{ }^{-}$and $\mathrm{NH}_{4}{ }^{+}$in soil samples is very important in order to control and optimize nutrient availability for plants and determine production and consumption rate related to the $\mathrm{N}$ cycle. Various conventional techniques are used to routinely detect $\mathrm{NO}_{3}{ }^{-}$and $\mathrm{NH}_{4}{ }^{+}$ such as liquid chromatography (IC), flow injection analysis (FIA), colorimetric assay etc. A recent report demonstrates the use of electrochemical impedance spectroscopy (EIS)-based sensors for direct sensing of $\mathrm{NO}_{3}{ }^{-}$in a controlled tree nursery environment and in a certified growing medium [6]. However, these techniques have some drawbacks. For example, farmers have very limited access to IC and FIA due to their cost and complexity of operation [7]. Even colorimetric assays that are typically marketed as suitable for in field use are typically used for research purposes. In our admittedly limited and anecdotal experience, farmers perceive colorimetric assays as complex and expensive. We will analyze procedures for sample analysis by both techniques later in the text. Therefore, the sensitive, simple and inexpensive method is highly required for $\mathrm{NO}_{3}{ }^{-}$and $\mathrm{NH}_{4}{ }^{+}$detection.

Ion selective electrodes (ISEs) are an alternative chemical sensor to detect the analytes which are easy to manufacture, show excellent sensitivity and selectivity, and ability to connect to simple communication devices [8-10]. ISEs are have been widely used in many fields (most significantly in clinical analysis, although applications in agriculture, food processing, and pollution monitoring are relevant too). Practitioners intending to apply ISEs in the field are typically critical of ISEs' robustness and precision [11]. A significant amount of work has been done in recent years to address some of the common criticism [12-16]. Reducing the complexness of operation with ISEs with the view of reducing farmers' distrust of analytical instrumentation is in a focus of our group. For example, we have very recently demonstrated a very simple substrate for ISEs that uses only materials available in common households [17].

We strongly believe that materials will continue to have major role in developing extremely simple sensing devices while in the same time significantly improving their functionality. For example, conductive polymers and carbon nanotubes has pushed boundaries of ISEs development $[18,19]$. In another example, acrylate-based polymers have enabled excellent improvements in ISEs while ionic liquids (ILs) are coming into fashion [20,21]. The later show promise due to almost unlimited structural differences thus changing functionality and analytical performance of ISEs [22]. Interestingly, currently there is a debate on actual role of ILs, as they have been successfully utilized as almost any major component of ISEs (ionophore, ion exchanger, plasticizer) [23-25]. Acrylate-based ISEs showed significant improvements sensitivity and selectivity over some of the traditionally used materials [26,27]. For example, a plasticizer-free polymer membrane composition based on a methyl methacrylate and decyl methacrylate (MMA-DMA) copolymer proposed by Bakker's group [28,29] exhibited improvement in sensing characteristics, while also improving the simplicity of sensor preparation and handling [30] has thus emerged as an excellent material for demonstrating ultra-simple sensors for in field use.

Herein, we study the role and the influence of two types of phosphonium-based ILs: (trihexyl(tetradecyl)phosphoniumbis(trifluoromethanesulfonyl) $\left[\mathrm{P}_{6,6,6,614}\right][\mathrm{TFMS}]$ and trihexyl(tetradecyl) 
phosphoniumdicyanamide[ $\left.\left.\mathrm{P}_{6,6,6,14}\right][\mathrm{DCA}]\right)$. We use them as plasticizers in view of improvement of robustness and sensing properties of ISEs. In addition, we utilized MMA-DMA to prepare ISEs that require almost no handling prior- and post-operation with the view of development of sensors that farmers can deploy on their fields. For this purpose, we utilized our substrate made of house-hold materials. We hope to develop sensors that will be sufficiently sensitive and robust, and that can be used at home by non-trained personnel (e.g., farmers). Ideally, they will be very simple for handling, thus reducing farmers' stress and wariness of complex analytical instrumentation. We demonstrated our sensors in direct, simultaneous analysis of $\mathrm{NO}_{3}{ }^{-}$and $\mathrm{NH}_{4}{ }^{+}$in a number of agriculturally-relevant soil and water samples.

\section{Experimental}

\subsection{Reagents}

Ionic liquids including trihexyl (tetradecyl) phosphoniumbis (trifluoromethanesulfonyl) $\left[\mathrm{P}_{6,6,6,14}\right]$ [TFMS] and trihexyl (tetradecyl) phosphoniumdicyanamide $\left[\mathrm{P}_{6,6,6,14}\right][\mathrm{DCA}]$ were purchased from Strem chemicals (purities > 95\%, Cambridge, UK), Tetradodecylammonium chloride (TDACl), poly(vinyl chloride) (PVC), bis(2-ethylhexyl)sebacate (DOS)(Fluka), Nonactin (ammonium ionophore I), and tetradodecylammonium tetrakis(4-chlorophenyl)borate (ETH 500) were obtained from Sigma-Aldrich (Gillingham, UK). Methyl methacrylatedecyl methacrylate (MMA-DMA) copolymer matrix and sodium tetrakis[3,5-bis- (trifluoromethyl)-phenyl]borate (NaTFPB) were obtained from Euvive (Aurora, CO 80045, USA). Tetrahydrofuran (THF) was obtained from Fisher (Loughborough, UK). All aqueous solutions were prepared in ultrapure water obtained from Pico Pure 3 water system.

\subsection{Preparation of Pencil-Drawn Electrodes}

The pencil-drawn electrodes were prepared as described previously [17]. Briefly, a cellulose acetate sheet, otherwise known under commercial name 'acetate' (used in variety of hobbies and available in most bookstores), was cut in small pieces $(1.5 \times 3.0 \mathrm{~cm})$ to form a single electrode. It was then etched with aluminum oxide (grit 240) for $30 \mathrm{~s}$ to provide rough surface in order to enable better adhesion of graphite onto its surface. A line is then drawn using regular graphite pencil (type 3B) by hand. The consistency of the line was checked by measuring of its resistance with a simple multimeter. If the resistance was higher than $5 \mathrm{k} \Omega$ (or measurements indicated that the line is not continuous), more graphite was added by further abrasion. The line was insulated using sellotape, making sure that the top end is left opened for connection with the instrument via alligator clips. A hole of $\sim 0.30 \mathrm{~cm}$ in diameter was punched at the distal end of the sellotape prior adhesion. The sellotape was carefully placed so that the hole aligned with the graphite line. This hole was used to deposit the cocktail which was prepared as described in Section 2.3. The procedure for the preparation of single electrodes is illustrated in Scheme 1, although we have also prepared sensing strips for the simultaneous analysis of $\mathrm{NO}_{3}{ }^{-}$and $\mathrm{NH}_{4}{ }^{+}$ions, as illustrated earlier [17].

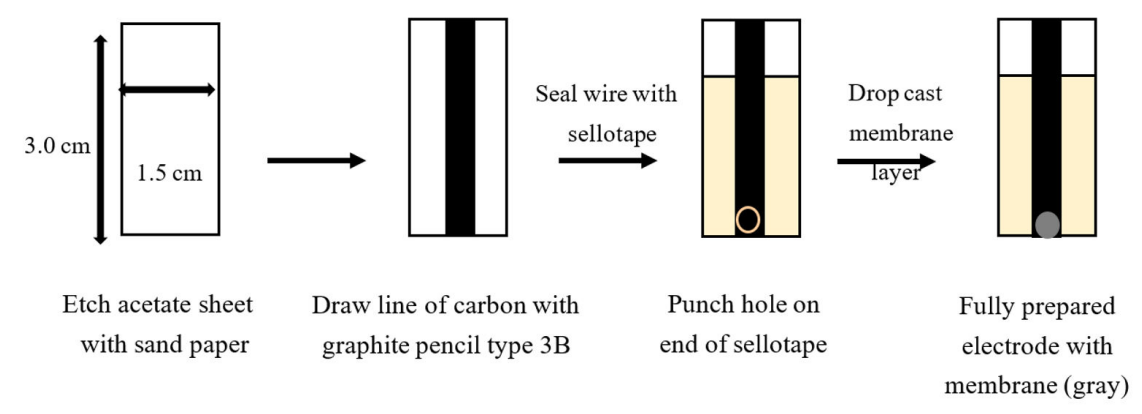

Scheme 1. Schematic representation of pencil-drawn ion selective electrode. 


\subsection{Preparation of Sensing Membrane for Nitrate and Ammonium Detection}

Table 1 presents the composition of all membranes used here. Total mass of all membranes was $200 \mathrm{mg}$. All chemicals of every membranes were immediately dissolved in $1.0 \mathrm{~mL}$ of THF, and the resulting cocktail was vortexed for $30 \mathrm{~min}$ to complete the dissolution of component. Then, the components solution was drop cast onto the substrate until the membrane thickness is $\sim 200 \mu \mathrm{m}$ and left it to dry at room temperature overnight. Electrodes were conditioned in $1.0 \times 10^{-3} \mathrm{M}$ of $\mathrm{NH}_{4} \mathrm{NO}_{3}$ for $12 \mathrm{~h}$ prior the use. Electrodes used for optimizing limit of detection (LOD) underwent additional conditioning step consisting of overnight conditioning in the mixture solution of $1.0 \times 10^{-8}$ of $\mathrm{NH}_{4} \mathrm{NO}_{3}$ and $1.0 \times 10^{-3}$ of $\mathrm{NaNO}_{3}$.

Table 1. Composition of membrane cocktails used in this work. Note that IL stands for both $\left[\mathrm{P}_{6,6,6,14}\right][$ TFMS $]$ and $\left[\mathrm{P}_{6,6,6,14}\right][\mathrm{DCA}]$. In other words, two membranes, each with separate IL, are prepared.

\begin{tabular}{|c|c|c|c|c|c|c|c|}
\hline \multirow[t]{2}{*}{ Membrane } & \multirow{2}{*}{$\begin{array}{c}\text { Ammonium I } \\
\text { Ionophore }\end{array}$} & \multirow{2}{*}{$\begin{array}{c}\begin{array}{c}\text { Additive } \\
\text { (ETH 500) }\end{array} \\
\begin{array}{c}\text { Concentration } \\
\text { (mmol/kg) }\end{array}\end{array}$} & \multicolumn{2}{|c|}{ Ion Exchanger } & \multicolumn{2}{|c|}{ Plasticizer } & \multirow[t]{2}{*}{ Polymer } \\
\hline & & & Type & $\begin{array}{c}\text { Concentration } \\
(\mathrm{mmol} / \mathrm{kg})\end{array}$ & Type & $\begin{array}{c}\text { Concentration } \\
(w t \%)\end{array}$ & \\
\hline 1 & & & TDACl & 5 & DOS & 66 & PVC \\
\hline 2,3 & & & TDACl & 5 & IL & 66 & PVC \\
\hline 4,5 & & & TDACl & 5 & DOS+IL & $33+33$ & PVC \\
\hline 5,6 & & & IL & 5 & DOS & 66 & PVC \\
\hline 7 & 10 & & NaTFPB & 5 & DOS & 66 & PVC \\
\hline 8,9 & 10 & & NaTFPB & 5 & IL & 66 & PVC \\
\hline 10,11 & 10 & & NaTFPB & 5 & DOS+IL & $33+33$ & PVC \\
\hline 12 & & 10 & TDACl & 5 & & N/A & MMA-DMA \\
\hline 13 & 10 & 10 & NaTFPB & 5 & & N/A & MMA-DMA \\
\hline
\end{tabular}

\subsection{EMF Measurements}

Potentiometric responses of all electrodes were record using the Lawson Labs Inc (Malvern, PA 19355, USA). 16-channel EMF-16 interface (3217 Phoenixville Pike, Malvern, PA, USA) in the stirred solution against a double-junction $\mathrm{Ag} / \mathrm{AgCl}$ reference electrode with a 1.0 M of LiOAc bridge electrolyte (Fluka). All ISEs were immersed into $20.0 \mathrm{~mL}$ of ultra-pure water in a beaker followed by stepwise addition of known concentration of $\mathrm{NH}_{4} \mathrm{NO}_{3}$. Electrodes were rinsed with ultra-pure water before immersing into the next sample to avoid carryovers. Activity coefficients (log a) were calculated according to the Debye-Hückel approach and voltages were corrected for liquid-junction potentials with the Henderson equation. All measurements are done using at least 6 electrodes of the same kind at a time.

\subsection{Analysis of $\mathrm{NO}_{3}{ }^{-}$and $\mathrm{NH}_{4}{ }^{+}$in Soil and Water Samples Using ISEs}

\subsubsection{Study Sites and Sampling}

All environmental water and soil sample were collected at Birmingham Institute for Forest Research (BIFoR) as noted on the map (Figure 1). 


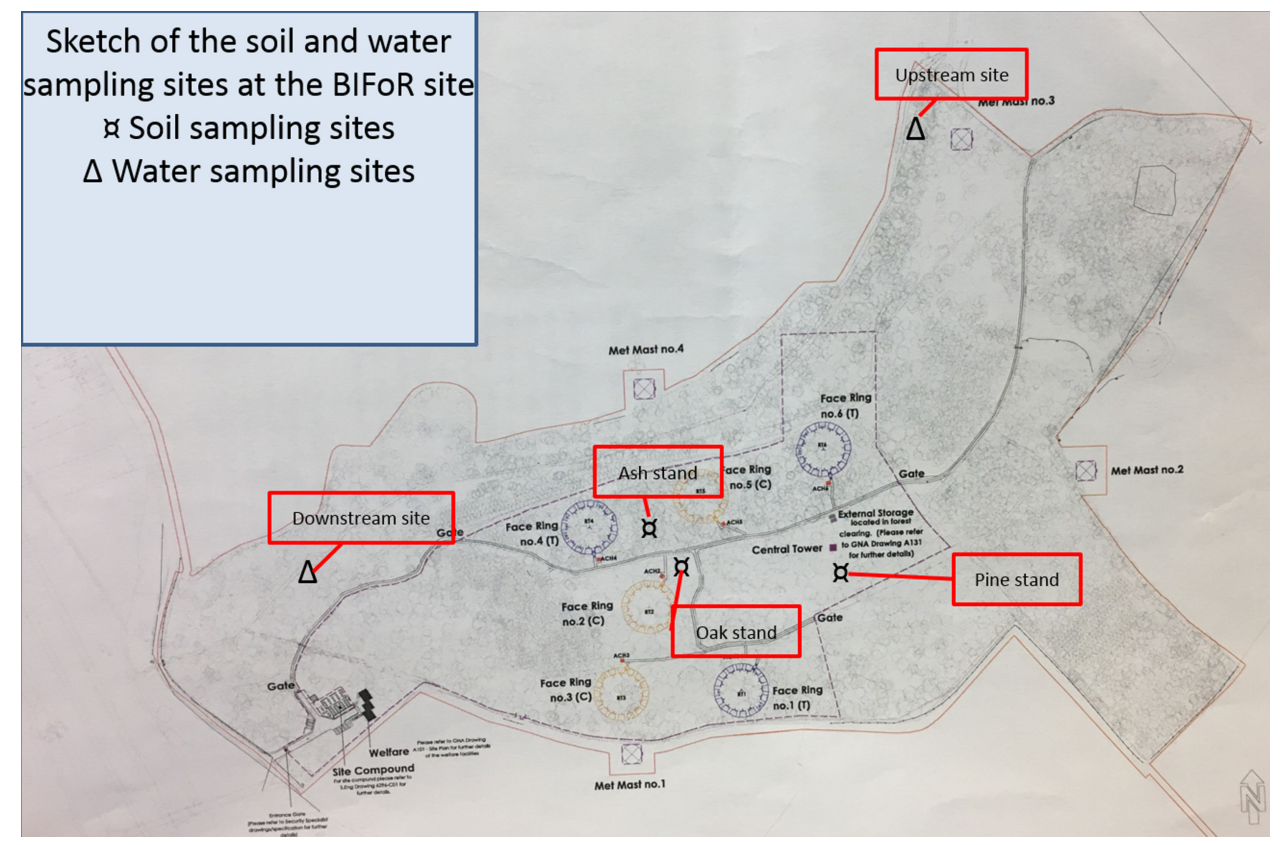

Figure 1. Map of BIFoR site with note water and soil sampling sites. Note that FACE Rings stand for Free-Air Carbon Dioxide Enrichment (FACE). They are a series of approximately cylindrical ring structures, as high as the tree canopy (around $25 \mathrm{~m}$ ) and $30 \mathrm{~m}$ wide, supporting pipes that deliver $\mathrm{CO}_{2}$ in such a way that the woodland inside the ring is immersed in elevated $\mathrm{CO}_{2}$, but the rest of the woodland remains largely unaffected. For more details, the reader is kindly asked to visit BIFoR's web site [31].

We collected a total of 8 water samples (four upstream (US) and four downstream (DS)) from the stream going through the site. We also collected total of 15 soil samples. Five samples were taken from each site rich with Scottish Pine (SP), Ash (ASH), and Oak (OAK).

Prior to sampling of soils, the overlying vegetation cover was removed and one soil core $(2-15 \mathrm{~cm}$ depth; $5 \mathrm{~cm}$ diameter) was collected for each sample plot using a hand auger. The soils were collected, homogenized by manual mixing, and stored in gas permeable polyethylene bags before laboratory analysis. All samples, one travel blank, and two filter blanks were transferred on ice to the laboratory within $2 \mathrm{~h}$ of collection, where they were refrigerated at $<5{ }^{\circ} \mathrm{C}$ until needed for the experimental procedures. Immediately prior to use, the soil was sieved to $4 \mathrm{~mm}$ to remove plant materials, large stones, and earthworms and then thoroughly mixed.

Aqueous samples were sampled according to standard water sampling procedure [32,33].

\subsubsection{Background Soil Analysis}

The main physico-chemical soil analysis were performed on air-dried soils, and according to established methods [34]. Soil moisture content was measured gravimetrically as moisture lost from a subsample of air-dried soils by continuous heating $\left(105^{\circ} \mathrm{C}\right)$ for up to $24 \mathrm{~h}$ until constant weight was achieved. Soil $\mathrm{pH}$ was measured at (soil:water mix $=1: 2.5$ ) by a standard $\mathrm{pH}$ probe. For all analysis, samples were blank corrected, and the level of precision was calculated as presented in Table 2.

Table 2. Background soil analysis for soils collected at BIFoR. Results obtained are average for at least four replicates sampled for each sample location.

\begin{tabular}{ccc}
\hline Soil Sample & $\mathbf{p H}$ & $\mathbf{( g / g )}$ \\
\cline { 3 - 3 } & & $0.35 \pm 0.04$ \\
Ash & $6.14 \pm 0.04$ & $0.29 \pm 0.05$ \\
Oak & $5.86 \pm 0.02$ & $0.14 \pm 0.03$ \\
\hline Scottish pine & $6.03 \pm 0.02$ & Moisture Content \\
\hline
\end{tabular}




\subsubsection{Extraction Procedure of $\mathrm{NH}_{4}{ }^{+}$and $\mathrm{NO}_{3}{ }^{-}$from Soil}

A standard methodology for extraction of reactive nitrogen $(\mathrm{Nr})$ requires solution of $2 \mathrm{M} \mathrm{KCl}$. Due to the selectivity (please see below), we used $0.1 \mathrm{M} \mathrm{MgSO}_{4}$ as a single extracting medium for simultaneous extraction of $\mathrm{NH}_{4}{ }^{+}$and $\mathrm{NO}_{3}{ }^{-}$. In all cases, $20 \mathrm{~g}$ of air-dried sieved $(<2 \mathrm{~mm})$ soil were weighed into 250-mL HDPE Nalgene bottles. This was followed by extraction of $\mathrm{Nr}$ from soil samples using $100 \mathrm{~mL}$ of chosen solution. Briefly, the soil slurries (a combination of soil sample and extractant) were continuously shaken on a reciprocating shaker at $200 \mathrm{rpm}$ for $1 \mathrm{~h}$ before being centrifuged at $4000 \mathrm{rpm}$ for $30 \mathrm{~min}$, followed by a two-step filtration into $20 \mathrm{~mL}$ scintillation vials through a no. 42 Whatman filter paper, and then 0.45 micron syringe filters (Whatman, Cambridge, UK). All analyses were carried out immediately unless otherwise stated, i.e., when samples were frozen until analysis.

\subsubsection{Analysis of $\mathrm{NH}_{4}{ }^{+}$and $\mathrm{NO}_{3}{ }^{-}$Using ISEs}

The unknown concentrations of $\mathrm{NO}_{3}{ }^{-}$and $\mathrm{NH}_{4}{ }^{+}$were determined using the standard addition method. Twenty milliliters of sample solution was spiked with $60.0 \mu \mathrm{L}$ of stock solution $(0.1 \mathrm{M}$ $\mathrm{NH}_{4} \mathrm{NO}_{3}$ ) until the potential change around $30-50 \mathrm{mV}$ to give final concentration of $\mathrm{NO}_{3}{ }^{-}$and $\mathrm{NH}_{4}{ }^{+}$ by neglecting the original concentration of analyte in samples. The unknown concentration was estimated by using the linear regression analysis. All results of $\mathrm{NO}_{3}{ }^{-}$and $\mathrm{NH}_{4}{ }^{+}$from the developed method were compared with the standard analytical methods.

\subsection{Analysis of $\mathrm{NO}_{3}{ }^{-}$and $\mathrm{NH}_{4}{ }^{+}$in Water and Soil Samples Using Portable Colorimetric Assays}

The sample concentration of $\mathrm{NO}_{3}{ }^{-}$and $\mathrm{NH}_{4}{ }^{+}$was validated using portable colorimetric assays. For $\mathrm{NH}_{4}{ }^{+}$detection, the commercial LCK 303 (HACH LANGE GMBH, Manchester, UK) was used as follows; the cap zip of the commercial tube was unscrewed and carefully removed the foil from the screwed-on cap zip. Then, $0.2 \mathrm{~mL}$ of sample was pipetted into the tube and the cap was immediately screwed back by fluting at the top. After that, the tube was shaken 2-3 times and left at room temperature for $15 \mathrm{~min}$. Finally, the outside of the tube was cleaned with paper and placed into the reader. The method offered linearity in the range of 2.5-60.0 mg/L. For $\mathrm{NO}_{3}{ }^{-}$detection, Palintest photometer 7100 (PHOT.23. AUTO, Gateshead, UK) was used. Briefly, the Nitratest tube was filled until $20.0 \mathrm{~mL}$ mark. One leveled spoon of Nitratest powder, and one Nitratest tablet was added; the tube was shaken for one minute and left for five minutes or longer to ensure complete settlement of powders and to obtain clear solution. The latter was carefully decanted into a round test tube and filled to $10.0 \mathrm{~mL}$ mark of tube. One Nitricol tablet was crushed and dissolved in $10.0 \mathrm{~mL}$ of clear solution. The tube was left for $10.0 \mathrm{~min}$ for color to fully develop. Finally, the tube was placed into the detector. The method allowed linearity over a range $0-20 \mathrm{mg} / \mathrm{L}$ of $\mathrm{NO}_{3}{ }^{-}$.

\subsection{Selectivity Measurements}

The selectivity was determined using separate solution method as suggested by Bakker [35]. Upon conditioning in $0.1 \mathrm{M}$ of $\mathrm{NaCl}$ solution, electrode response was determined for each interfering ions separately. In the case of $\mathrm{NO}_{3}{ }^{-}$response was collected in the following sequence of ions: $\mathrm{Cl}^{-}, \mathrm{SO}_{4}{ }^{2-}$, $\mathrm{NO}_{2}{ }^{-}, \mathrm{OH}^{-}, \mathrm{NO}_{3}{ }^{-}$, while in the case of $\mathrm{NH}_{4}{ }^{+}$, the sequence was: $\mathrm{Na}^{+}, \mathrm{Ca}^{2+}, \mathrm{H}^{+}, \mathrm{K}^{+}$, and $\mathrm{NH}_{4}{ }^{+}$.

\section{Results and Discussion}

\subsection{The Role of ILs in ISE}

In one of our previous works, we studied the influence of nine different ILs on selectivity on anion-selective electrodes [36]. In that work, we utilized ILs as plasticizers in ionopphore-free membranes and speculated that polarity of ILs was the key factor influencing selectivity. Building on that work, we decided to use IL-based membranes for development of $\mathrm{NH}_{4}{ }^{+}$- and $\mathrm{NO}_{3}{ }^{-}$-selective 
electrodes (membranes 2, 3, 8, and 9 from Table 1). In preparing $\mathrm{NO}_{3}{ }^{-}$-selective electrodes, we continued our practice of preparing ionophore-free membranes, which is also on accordance with common practice for preparing $\mathrm{NO}_{3}{ }^{-}$-selective electrodes. As expected, these electrodes showed Nernstian response slope and exhibits near-Nernstian slope with a detection limit of $5.5 \times 10^{-6} \mathrm{M}$ $(0.2 \mathrm{ppm})$. The response of one such electrode can be seen in Figure 2 (full circles). However, the situation with $\mathrm{NH}_{4}{ }^{+}$-selective electrodes was not so straightforward. Namely, no electrode containing substantial amounts of ILs as plasticizer (membranes 8, 9, 10, and 11) showed Nernstian response. A typical response for $\mathrm{NH}_{4}{ }^{+}$-selective electrodes is seen in Figure 1 (open circles). It should be noted that the response was not well-defined, and the electrodes exhibited a substantial amount of drift. We then re-evaluated the response of electrodes prepared using classical compositions (membranes 1 and 7), and obtained expected responses (data not shown). These results prompted us to reconsider and rethink the role of IL in an ISE. It is known that ILs can partition into water as observed and carefully evaluated in the group of Kakiuchi [37]. We speculated that cations and anions from the ILs utilized in this study do not partition in water in equal measure due to significant differences in their lipophilicities. In other words, if the cation in the IL is significantly more lipophilic than the anion, the sensor will respond to $\mathrm{NO}_{3}{ }^{-}$, but not to $\mathrm{NH}_{4}{ }^{+}$, thus effectively behaving as ion exchange membrane. Indeed, when we prepared membranes containing $5 \mathrm{mmol} / \mathrm{kg}$ of IL and PVC-DOS-based matrix (membranes 5, 6), the response was anionic (data not shown). Therefore, this led us to conclude that although ILs can dissolve PVC and effectively behave as plasticizers, they have strong influence of functionality due to exchange of ions. Therefore, they are suitable as ion exchangers, but their use as plasticizers is severely limited and dependent on the specific IL.

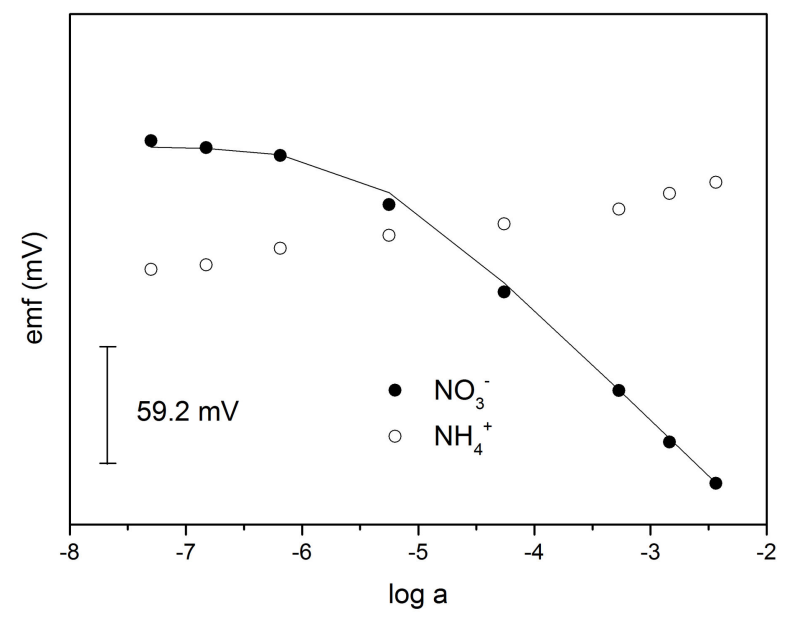

Figure 2. Response curves of $\mathrm{NO}_{3}{ }^{-}$- and $\mathrm{NH}_{4}{ }^{+}$-selective electrodes made of membranes 2 and 8 respectively.

\subsection{MMA-DMA-Based ISE and Determination of $\mathrm{NO}_{3}{ }^{-}$and $\mathrm{NH}_{4}{ }^{+}$in Water and Soil Samples}

In light of above discussion, it is clear that the ILs used in this study present significant limitations for describing cation-selective electrodes. To address this limitation, we decided to utilize acrylate-based membranes in preparation of $\mathrm{NO}_{3}{ }^{-}$and $\mathrm{NH}_{4}{ }^{+}$ISEs suitable for analysis of environmental samples. Membranes based on MMA-DMA have been utilized in the past due to excellent mechanical properties, reduced leaching of membrane components, and improved limit of detection [28,29]. We prepared membranes 12 and 13 as $\mathrm{NO}_{3}{ }^{-}$and $\mathrm{NH}_{4}{ }^{+}$ISEs respectively. The role of lipophilic salt (ETH 500) is required in order to reduce the resistance of membrane [20]. Electrodes exhibited near-Nernstian slopes and detection limits of $5.0 \times 10^{-6} \mathrm{M}(0.2 \mathrm{ppm})$ and $4.0 \times 10^{-6} \mathrm{M}(0.07 \mathrm{ppm})$ for $\mathrm{NO}_{3}{ }^{-}$and $\mathrm{NH}^{+}$electrodes respectively which corresponded nicely to classical PVC-DOS-based electrodes [17]. 
Furthermore, Figure 3 shows potentiometric response of $\mathrm{NH}_{4}{ }^{+}$- and $\mathrm{NO}_{3}{ }^{-}$-selective electrodes to that are expected to be the most significant interferences in soil samples. Observation of near-Nernstian response slopes for all ions allowed us to calculate unbiased selectivity coefficients as shown in Table 3.

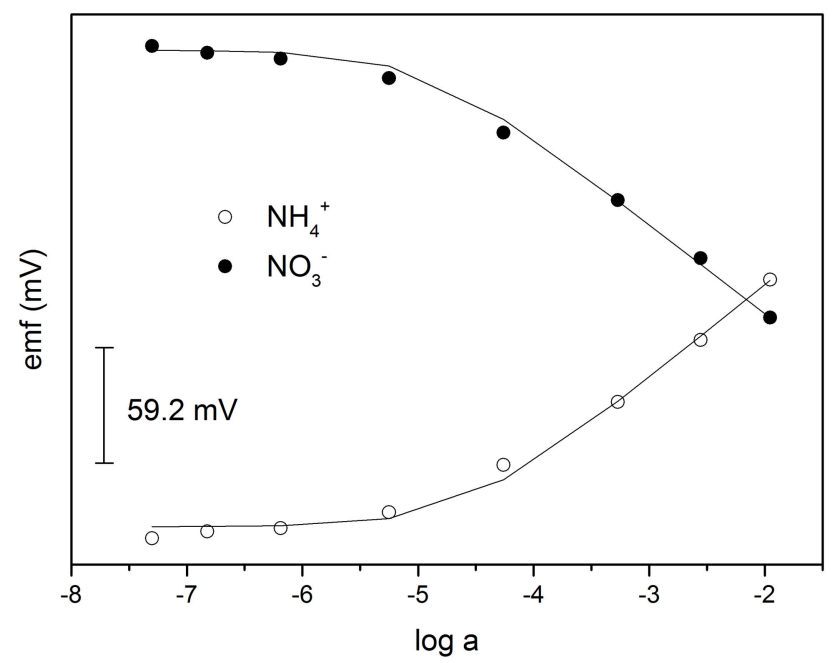

Figure 3. Response curves of $\mathrm{NO}_{3}{ }^{-}$- and $\mathrm{NH}_{4}{ }^{+}$- selective electrodes. All electrodes are prepared on acetate sheet/graphite substrate. Linear fit of calibration points is obtained by fitting classical Nikolsky equation and experimentally available parameters for slope, selectivity coefficients, and sample composition.

Table 3. Selectivity coefficients for selected ions obtained for $\mathrm{NH}_{4}{ }^{+}$- and $\mathrm{NO}_{3}{ }^{-}$-selective electrodes using acetate sheet/graphite- based substrate and MMA-DMA based membrane composition.

\begin{tabular}{cccccc}
\hline & $\mathbf{N H}_{\mathbf{4}}{ }^{+}$-Selective Electrode & \multicolumn{3}{c}{$\mathbf{N O}_{3}{ }^{-}$-Selective Electrode } \\
\hline Ion & Slope \pm S.D. & $\log K_{I, J}^{\text {pot }} \pm$ S.D. & Ion & Slope \pm S.D. & $\log K_{I, J}^{\text {pot }} \pm$ S.D. \\
$\mathrm{Na}^{+}$ & $45.67 \pm 1.0$ & $-1.56 \pm 0.01$ & $\mathrm{Cl}^{-}$ & $-42.89 \pm 0.9$ & $-2.24 \pm 0.05$ \\
$\mathrm{~K}^{+}$ & $46.88 \pm 1.5$ & $-0.65 \pm 0.20$ & $\mathrm{SO}_{4}{ }^{2-}$ & $-24.82 \pm 1.9$ & $-2.59 \pm 0.80$ \\
$\mathrm{Ca}^{2+}$ & $25.45 \pm 2.6$ & $-2.77 \pm 0.20$ & $\mathrm{NO}_{2}{ }^{-}$ & $-42.80 \pm 0.8$ & $-2.83 \pm 0.08$ \\
$\mathrm{NH}_{4}{ }^{+}$ & $52.96 \pm 0.5$ & 0 & $\mathrm{NO}_{3}{ }^{-}$ & $-49.45 \pm 1.3$ & 0 \\
\hline
\end{tabular}

3.3. Application of MMA-DMA-Based ISEs in Environmental Analysis and Comparison to Colorimetric Assay

Encouraged by these results, we decided to utilize MMA-DMA-based electrodes and determine concentration of $\mathrm{NO}_{3}{ }^{-}$and $\mathrm{NH}_{4}{ }^{+}$in real-life samples. We evaluated the results and procedures against colorimetric assays. The results are shown in Figures 4 and 5. 

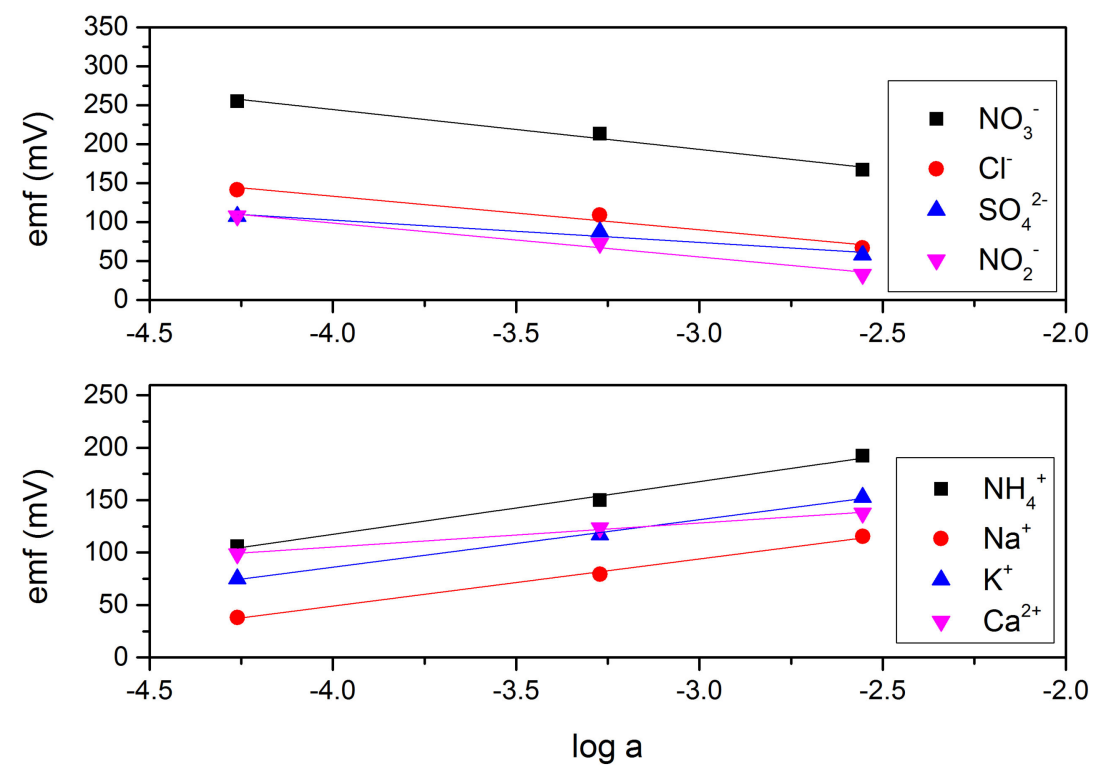

Figure 4. Potentiometric response for $\mathrm{NO}_{3}{ }^{-}$(top) —and $\mathrm{NH}_{4}{ }^{+}$(bottom) — selective electrodes to interfering ions.
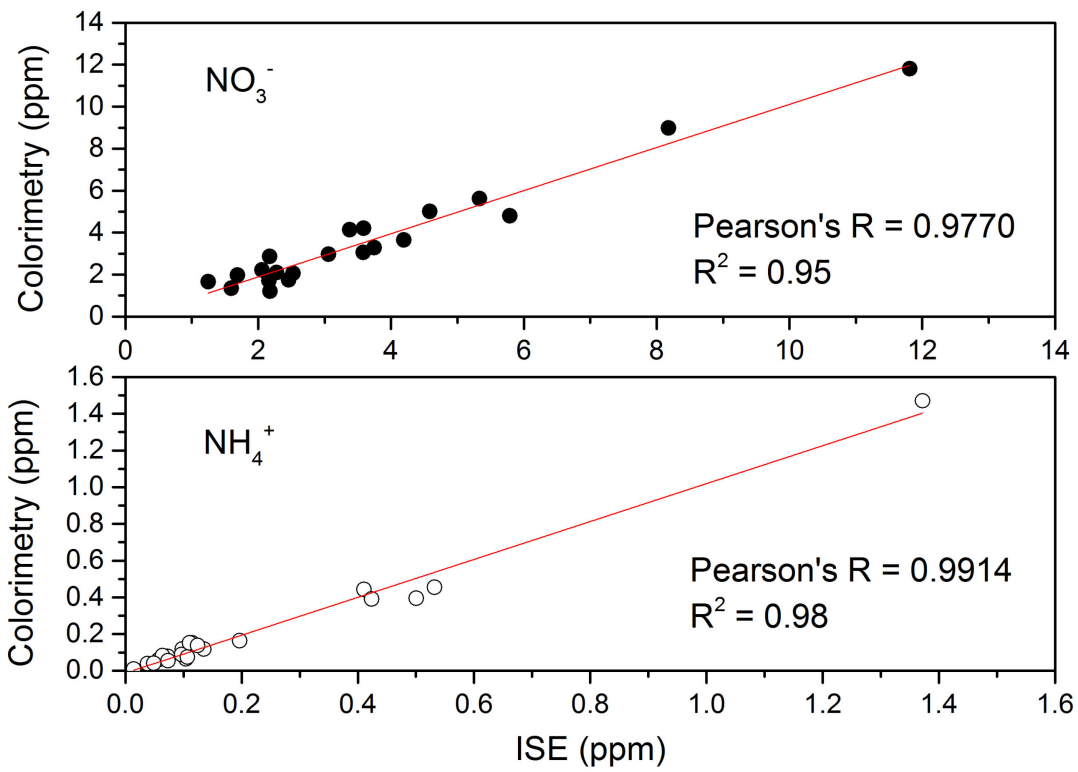

Figure 5. The comparison of the results obtained from determination of $\mathrm{NO}_{3}{ }^{-}$(top) and $\mathrm{NH}_{4}{ }^{+}$(bottom) in water and soil samples using the ISEs and portable techniques for 21 samples. In the case of ISEs, average values obtained from at least 3 different electrodes were used in this comparison.

We can see an excellent correspondence between the two techniques, indicating that ISEs can serve as alternative technique for simple determination of soil plant nutrients. However, let us compare and contrast procedures required for analysis by both techniques from the perspective of a non-trained person (e.g., farmer) and the convenience of the use on the field.

\subsubsection{Sample Preparation}

For analysis of soil samples, analytes (in this case $\mathrm{NH}_{4}{ }^{+}$and $\mathrm{NO}_{3}{ }^{-}$) have to first be extracted from the soil sample, typically by shaking of the sample in the presence of specified extractant (typically $1 \mathrm{M} \mathrm{KCl})$.

ISEs: From ISEs perspective, highly concentrated extractant such $1 \mathrm{M}$ solutions are not suitable due to the currently insufficient selectivity of $\mathrm{NH}_{4}{ }^{+}-$and $\mathrm{NO}_{3}{ }^{-}$-selective membranes. Thus, depending on 
the analyte and soil composition, a suitable extractant needs to be identified. Once a suitable extractant is identified, sample preparation for analysis by ISEs can be done in field.

Colorimetric assays: extraction of analyte must be followed by two-step filtering; initially through typical qualitative lab filter for removing bigger particles (e.g., Whatman Grade 1), followed by 0.45 microns syringe filters. This can be lengthy and tedious process, which is not realistically suitable for in field analysis.

\subsubsection{Sample Analysis}

ISEs: Drawing analogy from $\mathrm{pH}$ measurements, sample analysis is done by a simple dipping of the electrode into the sample solution and collecting the reading.

Colorimetric assays: It can be seen from Section 2.6. that analysis of $\mathrm{NH}_{4}{ }^{+}$involves a waiting step of $15 \mathrm{~min}$, while analysis of $\mathrm{NO}_{3}{ }^{-}$is even more complex, as it involves two steps: mixing the required chemicals with the sample, and waiting for pre-specified time. While this may not be problematic in the analysis of one sample, the length of analysis of multiple samples increases significantly. For example, in this work a fully trained $\mathrm{PhD}$ student took $\sim 3.5 \mathrm{~h}$ to complete analysis of 46 samples ( 23 sample for each of $\mathrm{NO}_{3}{ }^{-}$and $\mathrm{NH}_{4}{ }^{+}$ions) in a fully equipped lab. Therefore, it is easy to imagine that field analysis of large area can occupy significant amount of time.

\subsubsection{Precision and Efficiency}

ISEs: Dynamic range of ISEs can be multiple orders of magnitude, thus enabling the capture of wide concentration ranges. However, due to logarithmic dependence of signal versus the concentration, the precision is affected with pronounced negative effects if the concentration of the sample falls in the curvilinear response range [10]. The precision can be significantly improved if multiple ISEs of the same kind are used [38]. At present, only single ISEs are commercially available. However, due to the drive towards miniaturization, robustness, and simplicity of ISEs, it is easy to envision emergence of instrumentation containing multi-ISEs. This could be very important in the development of multi ion ISE assays, thus significantly simplifying while simultaneously improving precision of analysis.

Colorimetric assays: If the concentration in the sample falls in linearity range, the accuracy and precision of analysis is sufficient for routine analysis of nutrient level. However, if the concentration of the sample is outside of the range, the analysis complexity rises, as re-analysis is necessary. Furthermore, colorimetric assays are, by default, a single analyte analytical technique. Samples are analysed in a sequence of analytes.

\section{Conclusions}

Here, we have demonstrated that ILs with significant differences in polarity of cationic and anionic part can not be used as plasticizer. The more polar ion can be exchanged with the analyte, thus creating an ion exchanger. However, acrylate-based polymers are shown to be excellent materials for preparing plasticizer-free ISEs. We have prepared MMA-DMA-based, $\mathrm{NH}_{4}{ }^{+}$- and $\mathrm{NO}_{3}{ }^{-}$-selective ISEs using electrode substrates prepared using house-hold materials. We have demonstrated their functionality by analyzing 8 water and 15 soil samples. A comparison of results using ISEs and colorimetric assay showed excellent correlation (Pearson's $\mathrm{R}=0.97$ and 0.99 for $\mathrm{NO}_{3}{ }^{-}$and $\mathrm{NH}_{4}{ }^{+}$ions respectively). Here, we have shown that due to the simplicity of operation and handling protocols, ISEs are in strong position to become the leading technique for quick and easy in field analyses, even by non-trained personnel.

Author Contributions: A.N., P.T., P.K., T.R., S.U., and A.R. conceived and designed experiments, J.C. performed experiments, T.R., S.U., and A.R. analyzed the data, J.C. wrote the paper.

Funding: Authors are thankful for funds provided by British Council, Newton Fund, (grant \#261867079) and The Thailand Research Fund (grant no. PDG60W0017).

Conflicts of Interest: The authors declare no conflicts of interest. 


\section{References}

1. Sutton, M.A.; Bleeker, A.; Howard, C.M.; Erisman, J.W.; Abrol, Y.P.; Bekunda, M.; Datta, A.; Davidson, E.; de Vries, W.; Oenema, O.; et al. Our Nutrient World: The Challenge to Produce More Food and Energy With Less Pollution; Centre for Ecology \& Hydrology: Lancaster, UK, 2013; ISBN 978-1-906698-40-9.

2. Wang, Z.H.; Miao, Y.; Li, S.X. Wheat responses to ammonium and nitrate $\mathrm{N}$ applied at different sown and input times. Field Crops Res. 2016, 199, 10-20. [CrossRef]

3. García-Robledo, E.; Corzo, A.; Papaspyrou, S. A fast and direct spectrophotometric method for the sequential determination of nitrate and nitrite at low concentrations in small volumes. Mar. Chem. 2014, 162, 30-36. [CrossRef]

4. Tang, I.H.; Sundari, R.; Lintang, H.O.; Yuliati, L. Detection of nitrite and nitrate ions in water by graphene oxide as a potential fluorescence sensor. IOP Conf. Ser. Mater. Sci. Eng. 2016, 107, 012027. [CrossRef]

5. Martínková, E.; Křžek, T.; Coufal, P. Determination of nitrites and nitrates in drinking water using capillary electrophoresis. Chem. Pap. 2014, 68. [CrossRef]

6. Caron, W.O.; Lamhamedi, M.S.; Viens, J.; Messaddeq, Y. Practical Application of Electrochemical Nitrate Sensor under Laboratory and Forest Nursery Conditions. Sensors 2016, 16. [CrossRef] [PubMed]

7. López Pasquali, C.E.; Fernández Hernando, P.; Durand Alegría, J.S. Spectrophotometric simultaneous determination of nitrite, nitrate and ammonium in soils by flow injection analysis. Anal. Chim. Acta 2007, 600, 177-182. [CrossRef] [PubMed]

8. Diamond, D.; Coyle, S.; Scarmagnani, S.; Hayes, J. Wireless Sensor Networks and Chemo-/Biosensing. Chem. Rev. 2008, 108, 652-679. [CrossRef] [PubMed]

9. Fay, C.; Anastasova, S.; Slater, C.; Buda, S.T.; Shepherd, R.; Corcoran, B.; O'Connor, N.E.; Wallace, G.G.; Radu, A.; Diamond, D. Wireless ion-selective electrode autonomous sensing system. IEEE Sens. J. 2011, 11, 2374-2382. [CrossRef]

10. Radu, A.; Radu, T.; McGraw, C.M.; Dillingham, P.W.; Anastasova-Ivanova, S.; Diamond, D. Ion-Selective Electrodes in Environmental Analysis. J. Serb. Chem. Soc. 2013, 78, 1729-1761. [CrossRef]

11. Nitrate Sensing in the Soil. Available online: www.cambridgeconsultants.com/insights/nitrate-sensing-inthe-soil (accessed on 26 August 2018).

12. Cuartero, M.; Bakker, E. Environmental water analysis with membrane electrodes. Curr. Opin. Electrochem. 2017, 3, 97-105. [CrossRef]

13. Cuartero, M.; Pankratova, N.; Cherubini, T.; Crespo, G.A.; Massa, F.; Confalonieri, F.; Bakker, E. In Situ Detection of Species Relevant to the Carbon Cycle in Seawater with Submersible Potentiometric Probes. Environ. Sci. Technol. Lett. 2017, 4, 410-415. [CrossRef]

14. Mendecki, L.; Fayose, T.; Stockmal, K.A.; Wei, J.; Granados-Focil, S.; McGraw, C.M.; Radu, A. Robust and ultrasensitive polymer membrane-based carbonate-selective electrodes. Anal. Chem. 2015, 87, 7515-7518. [CrossRef] [PubMed]

15. Schazmann, B.; Demey, S.; Ali, Z.W.; Plissart, M.S.; Brennan, E.; Radu, A. Robust, Bridge-less Ion-selective Electrodes with Significantly Reduced Need for Pre-and Post-application Handling. Electroanalysis 2018, 30, 740-747. [CrossRef]

16. Wang, C.; Yuan, H.; Duan, Z.; Xiao, D. Integrated multi-ISE arrays with improved sensitivity, accuracy and precision. Sci. Rep. 2017, 7, 44771. [CrossRef] [PubMed]

17. Fayose, T.; Mendecki, L.; Ullah, S.; Radu, A. Single strip solid contact ion selective electrodes on a pencil-drawn electrode substrate. Anal. Methods 2017, 9, 1213-1220. [CrossRef]

18. Bobacka, J. Conducting Polymer-Based Solid-State Ion-Selective Electrodes. Electroanalysis 2006, 18, 7-18. [CrossRef]

19. Crespo, G.A.; Macho, S.; Rius, F.X. Ion-Selective Electrodes Using Carbon Nanotubes as Ion-to-Electron Transducers. Anal. Chem. 2008, 80, 1316-1322. [CrossRef] [PubMed]

20. Chumbimuni-Torres, K.Y.; Rubinova, N.; Radu, A.; Kubota, L.T.; Bakker, E. Solid contact potentiometric sensors for trace level measurements. Anal. Chem. 2006, 78, 1318-1322. [CrossRef] [PubMed]

21. Wei, D.; Ivaska, A. Applications of ionic liquids in electrochemical sensors. Anal. Chim. Acta 2008, 607, 126-135. [CrossRef] [PubMed]

22. Kakiuchi, T.; Tsujioka, N.; Kurita, S.; Iwami, Y. Phase-boundary potential across the nonpolarized interface between the room-temperature molten salt and water. Electrochem. Commun. 2003, 5, 159-164. [CrossRef] 
23. Shvedene, N.V.; Chernyshov, D.V.; Khrenova, M.G.; Formanovsky, A.A.; Baulin, V.E.; Pletnev, I.V. Ionic Liquids Plasticize and Bring Ion-Sensing Ability to Polymer Membranes of Selective Electrodes. Electroanalysis 2006, 18, 1416-1421. [CrossRef]

24. Peng, B.; Zhu, J.; Liu, X.; Qin, Y. Potentiometric response of ion-selective membranes with ionic liquids as ion-exchanger and plasticizer. Sens. Actuators B Chem. 2008, 133, 308-314. [CrossRef]

25. Shiddiky, M.J.; Torriero, A.A. Application of ionic liquids in electrochemical sensing systems. Biosens. Bioelectron. 2011, 26, 1775-1787. [CrossRef] [PubMed]

26. Heng, L.Y.; Hall, E.A. Producing “Self-Plasticizing” Ion-Selective Membranes. Anal. Chem. 2000, 72, 42-51. [CrossRef] [PubMed]

27. Heng, L.Y.; Hall, E.A. Taking the Plasticizer out of Methacrylic-Acrylic Membranes for K+-Selective Electrodes. Electroanalysis 2000,12, 187-193. [CrossRef]

28. Qin, Y.; Peper, S.; Radu, A.; Ceresa, A.; Bakker, E. Plasticizer-Free Polymer Containing a Covalently Immobilized Ca -Selective Ionophore for Potentiometric and Optical Sensors. Anal. Chem. 2003, 75, 3038-3045. [CrossRef] [PubMed]

29. Peper, S.; Ceresa, A.; Qin, Y.; Bakker, E. Plasticizer-free microspheres for ionophore-based sensing and extraction based on a methyl methacrylate-decyl methacrylate copolymer matrix. Anal. Chim. Acta 2003, 500, 127-136. [CrossRef]

30. Rich, M.; Mendecki, L.; Mensah, S.T.; Blanco-Martinez, E.; Armas, S.; Calvo-Marzal, P.; Radu, A.; Chumbimuni-Torres, K.Y. Circumventing traditional conditioning protocols in polymer membrane-based ion-selective electrodes. Anal. Chem. 2016, 88, 8404-8408. [CrossRef] [PubMed]

31. BIFoR FACE-Birmingham Institute of Forest Research-University of Birmingham. Available online: https:/ / www.birmingham.ac.uk/research/activity/bifor/face/index.aspx (accessed on 28 August 2018).

32. Korfmacher, J.L.; Musselman, R.C. Evaluation of Storage and Filtration Protocols for Alpine/Subalpine Lake Water Quality Samples. Environ. Monit. Assess. 2007, 131, 107-116. [CrossRef] [PubMed]

33. Wilson, B.; Gandhi, J.; Zhang, C.C. Analysis of inorganic nitrogen and related anions in high salinity water using ion chromatography with tandem UV and conductivity detectors. J. Chromatogr. Sci. 2011, 49, 596-602. [CrossRef] [PubMed]

34. Grizzetti, B.; Bouraoui, F.; Billen, G.; van Grinsven, H.; Cardoso, A.C.; Thieu, V.; Garnier, J.; Curtis, C.; Howarth, R.W.; Johnes, P. Nitrogen as a threat to European water quality. Available online: http: / centaur. reading.ac.uk/20869/1/28387ENA_c17.pdf (accessed on 1 June 2018).

35. Bakker, E. Determination of Unbiased Selectivity Coefficients of Neutral Carrier-Based Cation-Selective Electrodes. Anal. Chem. 1997, 69, 1061-1069. [CrossRef]

36. Mendecki, L.; Callan, N.; Ahern, M.; Schazmann, B.; Radu, A. Influence of Ionic Liquids on the Selectivity of Ion Exchange-Based Polymer Membrane Sensing Layers. Sensors 2016, 16, 1106. [CrossRef] [PubMed]

37. Kakiuchi, T.; Yoshimatsu, T.; Nishi, N. New Class of Ag/AgCl Electrodes Based on Hydrophobic Ionic Liquid Saturated with AgCl. Anal. Chem. 2007, 79, 7187-7191. [CrossRef] [PubMed]

38. Dillingham, P.W.; Radu, T.; Diamond, D.; Radu, A.; McGraw, C.M. Bayesian Methods for Ion Selective Electrodes. Electroanalysis 2012, 24, 316-324. [CrossRef]

(C) 2018 by the authors. Licensee MDPI, Basel, Switzerland. This article is an open access article distributed under the terms and conditions of the Creative Commons Attribution (CC BY) license (http://creativecommons.org/licenses/by/4.0/). 